\title{
The Iterative Method of Development Pattern and Anti- Pattern
}

\author{
Małgorzata MARKOWSKA \\ Wrocław University of Economics, Wrocław, Poland \\ \{malgorzata.markowska@ue.wroc.pl\}
}

\begin{abstract}
The ordering or ranking of multidimensional objects is a very popular subject of research. The first formal method was proposed by Hellwig [4]. He introduced the division of variables into stimulants (the bigger the better) and destimulants (the smaller the better). His main idea was to find the artificial object, called "development pattern" defined by the best values of variables. Then distances for all objects from the development pattern are calculated and objects are ranked according to the diminishing value of this distance. The next idea was to define the "development anti-pattern" - the artificial object defined by the worst values. Objects are ranked according to the growing distance from the antipattern. In the presence of outliers, at least in one variable, can have big influence on the final ranking. Such outliers introduce unexpected weighting system to the problem. If there is an object with one value very much bigger than the rest of the set, values of this variable - through standardization - are moved toward the other end of the distribution which becomes skewed. In order to avoid this problem we propose to use an iterative procedure. Objects are ranked one by one. We assigned just one rank to the best object on a given iteration of the procedure, and then this object is eliminated from the lot. The formula to calculate the composite index is given. The example deals with the measurement of innovation activity of provinces in Poland.
\end{abstract}

Keywords: Linear Ordering, Development Pattern, Multivariate Analysis.

\section{$1 \quad$ Introduction}

Linear ordering of objects based on composite indicator calculated from individual variables is used in different fields such as economy, quality of life, environment, development etc. The first method of linear ordering was proposed by Hellwig [4] in 1968. Generally not so many different approaches have been proposed in the literature since then. Saisana and Tarantola [11] list just six methods and they also give a review of some applications. TOPSIS approach (Hwang and Yoon [5]) and its fuzzy variants (Chen and Hwang [2]) can be added to this list. The crucial points in all procedures are as follows: selection of sub-indicators, normalization (or standardization) method, weighting system and aggregation formula. Uncertainty and sensitivity of choices with these steps has been studied by Saisana, Saltelli and Tarantola [10]. The most well- 
known composite index is a Human Development Index for world countries, proposed by Amartya Sen and Mahbub ul Haq, calculated and published since 1990 (See Sen [12], Sager and Najam [9], Stanton [13])

Markowska and Sokołowski [6] proposed an iterative method of multidimensional objects ordering using the most popular ordering method (OECD [8]), referred to in this paper as the classical one. The characteristics are made comparable by normalizing the distance from the worst object (the lowest value for stimulants and the highest for destimulants) by the range, for each characteristic separately. This operation brings down the values of all characteristics to the range $[0 ; 1]$ and changes destimulants into stimulants.

The aggregate index is calculated as an arithmetic mean, or a weighted arithmetic mean, if a reasonable weighting system can be proposed (e.g. expert weights). If the distributions of characteristics are very asymmetrical, or if outliers are present, an additional weighing factor is brought into the procedure. The importance of the negative asymmetric distribution is strengthened for the majority of characteristics, whereas those with strong positive asymmetric distribution - are weakened. The presented paper proposes defining the hierarchy of objects starting from the best one. Once assigned the subsequent rank, the object is removed from the working set, and thus the minimum or maximum reference points can be changed.

The goal of this study is to propose the application of an analogical iteration procedure to Hellwig's development pattern/anti-pattern method [4], and also to discuss the question regarding the extent to which the iterative procedure gives different results comparing to the original (non-iterative) Hellwig's approach. The empirical example provided has mainly an illustrative purpose, and not the comprehensive analysis of the problem considered.

\section{Method}

In the original development pattern method, firstly the characteristics are made comparable using standardization. Next the distances of objects to the development pattern defined by maximum stimulant values and minimum destimulant values, are calculated. The objects are ranked in a sequence from an object closest to the pattern to the one most distant from the pattern. The procedure of aggregate index calculation, in accordance with the classical ordering method, is presented in Fig. 1.
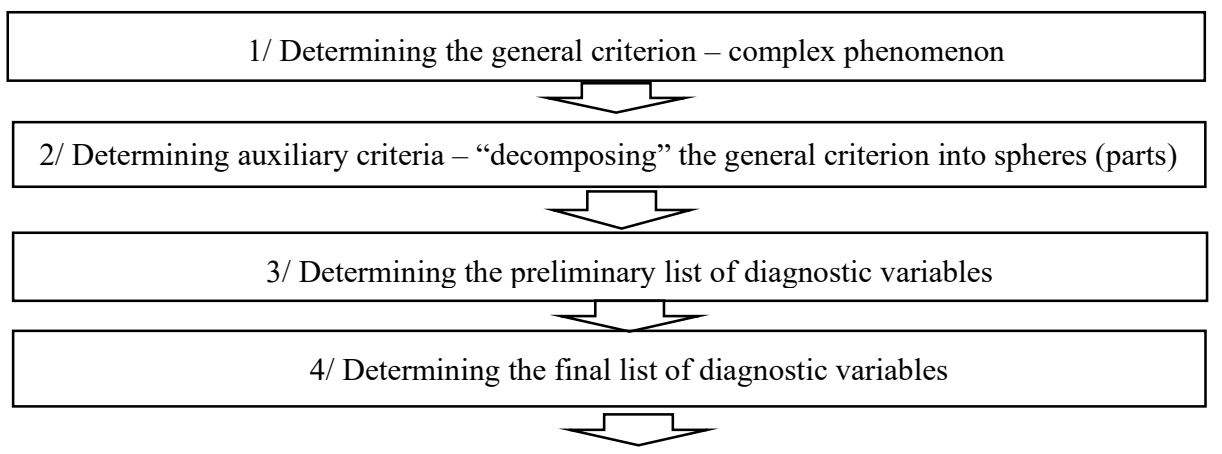
5/ Determining the nature of variables (stimulants, destimulants, nominants)

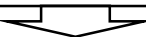

6/ Determining weights

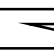

7/ Making the characteristics comparable

(normalization to the interval $[0 ; 1]$, standardization, quotient transformation)

8/ Aggregation of variables made comparable

Fig. 1. Aggregate index determining procedure.

At the stage of step no. 7 the characteristics are usually unified, i.e. transformed into stimulants. The following formulas are applied in the classical method:

$$
\begin{aligned}
& x_{i}^{*}=\frac{x_{i}-\min _{i}\left\{x_{i}\right\}}{\max _{i}\left\{x_{i}\right\}-\min _{i}\left\{x_{i}\right\}}, \\
& x_{i}^{*}=\frac{\max _{i}\left\{x_{i}\right\}-x_{i}}{\max _{i}\left\{x_{i}\right\}-\min _{i}\left\{x_{i}\right\}},
\end{aligned}
$$

forstimulants, (1)

for destimulants.

The next stage consists in the aggregation of variables made comparable - usually by using an additive formula taking the form of weighted arithmetic mean:

$$
W_{i}=\frac{s}{\sum_{j=1}^{m} a_{j}} \sum_{j=1}^{m} a_{j} x_{i j}^{*}
$$

where:

$i$ - object's number,

$W_{i}$ - value of aggregate index for $i$-th object,

$j$ - characteristic's number,

$m$ - number of characteristics,

$a_{j}$ - weight of $j$-th characteristics,

$x_{i j}$ - value of $X_{j}$ variable observed on $i$-th object (made comparable),

$s$ - scale factor (usually adopted as 1 or 100 ).

As a result, aggregate index values are calculated and can be ranked. Our proposal ranks objects individually, starting from the one "located" as the closest to the pattern. After finding the best object, it is eliminated from the list of the currently considered ones and standardization is carried out again. As a result, both the standardized values of characteristics and the pattern coordinates change. The following ranking positions are 
determined gradually, one in each iteration, and later the assigned object is eliminated from the set in which the next consecutive object is searched for. This method can be referred to as the moving pattern method. The values of aggregate index are determined according to the procedure presented in Figure 2.

The described algorithm is repeated until three worst objects, assigned to the last ranks, remain in the subset. The procedure requires proposing a new method for determining the aggregate index, in which while determining the $i$-th rank the following is calculated:

$$
D_{(i+1)}=\frac{W_{(i+1)}^{i}}{W_{(i)}^{i}}
$$

where:

$D_{(i+l)}$ - reduction ratio of aggregate index,

(i) $-i$-th rank,

$W_{(i)}^{i}$ - local aggregate index calculated when determining $i$ rank.

The final value of aggregate index is determined based on formula (5):

$$
W_{(k)}=W_{(1)}^{1} \prod_{i=2}^{k} D_{(i)}
$$

The values for subsequent objects are reduced according to the proportion resulting from the last joint comparison of the given and previous object (regarding the rank order).

The moving anti-pattern method of development works in a similar way, with the order of objects being determined from the worst object, i.e. the closest to development anti-pattern, determined by the smallest values of characteristics made comparable. Objects are removed from the set starting with $n$ ranked object.

1/ Determining the best object in the set - according to the procedure (see Fig. 1)

2/ Object elimination from the set

3/ Determining minimum and maximum values of characteristics in the current set (subset) of objects

4/ Finding the best object according to the classical procedure (described above)

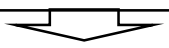

5/ Assigning this object with a subsequent rank

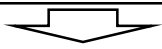


6/ Removing this object from the working set

7/ Returning to point 1

Fig. 2. Aggregate index determining procedure-moving pattern method.

Due to the fact that the purpose of the study is also to answer the question regarding the extent to which the iterative procedure gives different results than the original approach, one comparison is given here - based on statistical data used to develop the Relative Index of Enterprise Innovation Activity (RIEIA) proposed by Markowska and Strahl [7], in the part referring to industrial activity sphere (RIIEIA). The index covers 39 characteristics and a dual system of weights using expert weights and a hierarchical structure of characteristics. (Freudenberg [3] constructed an index of innovation performance based on 12 variables within three groups: generation of new knowledge, industry-science linkages / technology diffusion, industrial innovation).

The list of characteristics used in our example and the final values of weights are presented in Table 1.

Table 1. Variables used to develop the Relative Index of Industrial Enterprise Innovation Activity.

\begin{tabular}{|c|c|c|c|c|}
\hline & \multirow{2}{*}{ Variable } & \multicolumn{2}{|c|}{ Industry } & \multirow[b]{2}{*}{ Weight } \\
\hline & & Range & Poland & \\
\hline I & Enterprises investing in innovations & $10.9-16.4$ & 14.0 & 1.00 \\
\hline I & $\begin{array}{l}\text { Average innovation investments per enterprise in } 1000 \text { 's } \\
\text { PLN }\end{array}$ & $356-1362$ & 968 & 1.00 \\
\hline $\mathrm{P}$ & Enterprises receiving public financial support & $3.6-7.5$ & 4.9 & 1.00 \\
\hline $\mathrm{P}$ & $\begin{array}{l}\text { Enterprises receiving public financial support from } \\
\text { domestic institutions }\end{array}$ & $1.6-4.9$ & 2.7 & 0.50 \\
\hline $\mathrm{P}$ & $\begin{array}{l}\text { Enterprises receiving public financial support from local } \\
\text { authorities }\end{array}$ & $0.4-2.1$ & 1.0 & 0.25 \\
\hline $\mathrm{P}$ & $\begin{array}{l}\text { Enterprises receiving public financial support from central } \\
\text { authorities }\end{array}$ & $1.1-3.0$ & 1.9 & 0.25 \\
\hline $\mathrm{P}$ & Enterprises receiving public financial support from EU & $2.5-5.9$ & 3.7 & 0.50 \\
\hline $\mathrm{P}$ & $\begin{array}{l}\text { Enterprises receiving public financial support from } \\
\text { Horizon } 2020\end{array}$ & $0.0-1.3$ & 0.4 & 0.25 \\
\hline A & Innovation active enterprises & $14.5-23.1$ & 18.9 & 1.00 \\
\hline A & E.w.i. ${ }^{*}$ innovations & $13.7-21.5$ & 17.6 & 1.00 \\
\hline A & E.w.i. new products & 9.6-14.4 & 11.8 & 0.50 \\
\hline A & E.w.i. new processes & $6.8-13.8$ & 9.9 & 0.17 \\
\hline A & E.w.i new logistics & $1.8-4.7$ & 3.2 & 0.17 \\
\hline A & E.w.i supporting activities & $4.0-7.5$ & 5.9 & 0.17 \\
\hline A & E.w.i organisational or marketing innovations & $8.2-16.3$ & 11.4 & 1.00 \\
\hline A & E.w.i organisational innovations & $5.3-10.5$ & 8.1 & 0.50 \\
\hline A & E.w.i new business practices for organisational procedures & $3.6-8.2$ & 6.1 & 0.17 \\
\hline A & E.w.i. new methods in work responsibilities & $2.8-7.9$ & 5.0 & 0.17 \\
\hline A & E.w.i. new methods in external relations & $1.9-4.7$ & 3.1 & 0.17 \\
\hline A & E.w.i. marketing innovations & $4.7-12.5$ & 7.1 & 0.50 \\
\hline
\end{tabular}




\begin{tabular}{|c|c|c|c|c|}
\hline & \multirow{2}{*}{ Variable } & \multicolumn{2}{|c|}{ Industry } & \multirow{2}{*}{ Weight } \\
\hline & & Range & Poland & \\
\hline A & E.w.i. new packaging & $2.6-9.0$ & 4.2 & 0.13 \\
\hline A & E.w.i. new media and promotion & $1.7-6.8$ & 3.8 & 0.13 \\
\hline A & E.w.i. new product placement and sales & $1.1-3.7$ & 2.1 & 0.13 \\
\hline A & E.w.i. new pricing & $1.4-5.4$ & 2.7 & 0.13 \\
\hline $\mathrm{C}$ & Enterprises cooperating & $3.7-8.4$ & 5.5 & 1.00 \\
\hline $\mathrm{C}$ & $\begin{array}{l}\text { Enterprises cooperating for receiving access to intellectual } \\
\text { property }\end{array}$ & $0.1-0.3$ & 0.2 & 0.17 \\
\hline $\mathrm{C}$ & Enterprises benefiting from free intellectual property & $0.7-2.7$ & 1.4 & 0.17 \\
\hline $\mathrm{C}$ & Enterprises using innovations protected by exclusive rights & $1.6-3.7$ & 2.3 & 0.17 \\
\hline $\mathrm{E}$ & Revenues from products to the market & 3.6-18.3 & 9.5 & 0.50 \\
\hline $\mathrm{E}$ & Revenues from products new to the firm & $1.1-13.1$ & 5.5 & 0.50 \\
\hline $\mathrm{E}$ & Enterprises with applications for trademarks in Poland & $0.4-6.5$ & 3.0 & 1.00 \\
\hline $\mathrm{E}$ & $\begin{array}{l}\text { Enterprises with applications for industrial designs in } \\
\text { Poland }\end{array}$ & $0.5-5.3$ & 1.3 & 1.00 \\
\hline $\mathrm{E}$ & Enterprises with applications for utility models in Poland & $0.2-3.3$ & 1.0 & 1.00 \\
\hline $\mathrm{E}$ & Enterprises with applications for patents in Poland & $1.2-4.6$ & 2.3 & 1.00 \\
\hline $\mathrm{E}$ & Enterprises planning to apply for foreign patents & $0.1-2.8$ & 0.6 & 0.50 \\
\hline $\mathrm{E}$ & $\begin{array}{l}\text { Enterprises with Polish patent applications resulted from } \\
\text { internal R\&D activities }\end{array}$ & $1.1-3.7$ & 1.6 & 0.50 \\
\hline E & Enterprises which obtained patents in Poland & $1.0-4.9$ & 2.0 & 1.00 \\
\hline E & Enterprises which made application for foreign patent & $0.3-3.4$ & 1.0 & 1.00 \\
\hline $\mathrm{E}$ & Enterprises which obtained foreign patents & $0.1-3.0$ & 0.7 & 1.00 \\
\hline
\end{tabular}

\section{$3 \quad$ Results}

In the study [4] partial indexes were calculated for Polish regions at NUTS 2 level regarding such innovation areas as: investment outlays for innovation, public aid, innovative activity, cooperation in the field of innovation and the effects of innovative activities - for industry and separately for services. The statistical data used come from the short version of CIS (Community Innovation Survey) study [1], and are presented as percentages. The indexes were calculated using the classical normalization method to the interval $[0 ; 1]$, by a new iterative method, which defines the positions subsequently one after the other from the best object, and also using a rank (pointbased) method. The cited study discusses such methodological problems as: the consequences of abandoning normalization (in the situation, in the case when the characteristics taken into account in the assessment are presented as percentages and represent stimulants), the selection of variable weighing systems (when they are of hierarchical nature and percentages do not add up to 100 due to the multiple choice of variants), aggregating partial indexes into a global one.

Below, along with the results of the original pattern and anti-pattern development methods and their iterative versions, the results of the classical linear ordering method and its iterative version are presented following Markowska and Strahl [7] - Table 2. 
Table 2. The values of Relative Index of Industrial Enterprise Innovation Activity, calculated for Polish provinces, for 2015.

\begin{tabular}{lcccccc}
\hline \multirow{2}{*}{ Province } & \multicolumn{2}{c}{ Pattern method } & \multicolumn{2}{c}{ Anti-pattern method } & \multicolumn{2}{c}{ Classical method } \\
original & iterative & original & iterative & original & iterative \\
\hline Dolnośląskie & $\mathbf{2 5}$ & $\mathbf{2 3}$ & $\mathbf{6 3}$ & $\mathbf{6 6}^{*}$ & $\mathbf{5 4}$ & $\mathbf{5 1}$ \\
Kujawsko-pomorskie & 20 & 20 & $\underline{\mathbf{4 5}}$ & $\underline{\mathbf{3 3}}$ & 26 & 25 \\
Lubelskie & 15 & 14 & $\underline{\mathbf{4 3}}$ & $\underline{\mathbf{3 2}}$ & $\mathbf{3 2}$ & $\mathbf{2 8}$ \\
Lubuskie & 15 & 16 & $\underline{\mathbf{4 1}}$ & $\underline{\mathbf{3 1}}$ & $\mathbf{2 6}$ & $\mathbf{1 8}$ \\
Lódzkie & $\mathbf{1 3}$ & $\mathbf{1 5}$ & $\mathbf{3 4}$ & $\mathbf{2 5}$ & 24 & 24 \\
Małopolskie & $\mathbf{3 2}$ & $\mathbf{3 0}$ & 66 & 67 & $\mathbf{4 9}$ & $\mathbf{4 6}$ \\
Mazowieckie & $\mathbf{2 7}$ & $\mathbf{2 5}$ & $\mathbf{5 6}$ & $\mathbf{5 0}^{*}$ & 47 & 46 \\
Opolskie & $\mathbf{2 6}$ & $\mathbf{2 4}$ & $\mathbf{6 9}$ & $\mathbf{7 3}^{*}$ & 50 & 49 \\
Podkarpackie & $\mathbf{3 5}$ & $\mathbf{3 1}$ & $\underline{\mathbf{7 9}}$ & $\mathbf{9 2}^{*}$ & $\mathbf{6 2}$ & $\mathbf{5 7}$ \\
Podlaskie & 57 & 57 & 115 & 115 & 64 & 64 \\
Pomorskie & 25 & 24 & $\mathbf{5 4}$ & $\mathbf{4 8}$ & 32 & 31 \\
Śląskie & 42 & 42 & $\mathbf{7 5}$ & $\mathbf{7 8}^{*}$ & 59 & 59 \\
Świętokrzyskie & $\mathbf{4}$ & $\mathbf{1 0}$ & $\mathbf{2 5}$ & $\mathbf{1 8}^{*}$ & 11 & 10 \\
Warmińsko-mazurskie & 17 & 17 & $\underline{\mathbf{4 0}}$ & $\underline{\mathbf{3 0}}$ & 29 & 28 \\
Wielkopolskie & $\mathbf{2 7}$ & $\mathbf{2 5}$ & $\underline{\mathbf{5 4}}$ & $\underline{\mathbf{4 4}}$ & 36 & 36 \\
Zachodniopomorskie & $\mathbf{2 3}$ & $\mathbf{2 1}$ & $\mathbf{5 4}$ & $\mathbf{4 6}^{*}$ & $\mathbf{3 8}$ & $\mathbf{4 0}$ \\
\hline
\end{tabular}

The change by two or more is marked in bold, the changes in plus are marked with an asterisks, and the changes by 10 or more are underlined. Source: author's calculations and [7].

When calculating an index value using the original pattern and anti-pattern development method, the selection of reference distance remains the key problem. Hellwig [4] proposed the reference point to be the mean distance plus twice the standard deviation of the distance. The reference point from the original version of the aggregate index does not ensure that the index value is less than 1 (and not higher than 100 in the version adopted for this study). Podlaskie province is close to the pattern, far from the anti-pattern and the index value for this province is relatively small in case of the pattern method, and relatively high in case of the anti-pattern method. The additional factor causing this phenomenon is the effect of "inflating space" - the larger the space, the longer the distances between empirical points. In case of the studied problem the classification space is a 39-dimensional one. Podlaskie province is the best one in industrial innovation activity, so by definition, its composite index has the same value in both, iterative and non-iterative procedures.

The similarity of index values calculated using classical methods against the results of iterative methods was assessed using linear correlation coefficients. They are presented in Table 3.

All of them are statistically significant (correlation coefficients from 0.826 up to 0.989). 
Table 3. Linear correlation coefficients of innovation indexes.

\begin{tabular}{lccccccc}
\hline \multicolumn{2}{c}{ Specification } & \multicolumn{2}{c}{ Pattern method } & \multicolumn{2}{c}{$\begin{array}{c}\text { Anti-pattern } \\
\text { method }\end{array}$} & \multicolumn{2}{c}{ Classical method } \\
& & original & iterative & original & iterative & original & iterative \\
\hline Pattern & original & 1 & $\mathbf{0 . 9 8 5}$ & 0.967 & 0.931 & 0.884 & 0.901 \\
method & iterative & $\mathbf{0 . 9 8 5}$ & 1 & 0.950 & 0.910 & 0.826 & 0.848 \\
Anti-pattern & original & 0.967 & 0.950 & 1 & $\mathbf{0 . 9 8 1}$ & 0.908 & 0.910 \\
method & iterative & 0.931 & 0.910 & $\mathbf{0 . 9 8 1}$ & 1 & 0.941 & 0.934 \\
Classical & original & 0.884 & 0.826 & 0.908 & 0.941 & 1 & $\mathbf{0 . 9 8 9}$ \\
method & iterative & 0.901 & 0.848 & 0.910 & 0.934 & $\mathbf{0 . 9 8 9}$ & 1 \\
\hline
\end{tabular}

Correlation coefficients higher than 0.98 are marked in bold. Source: authors' calculations.

While comparing the original versions with the iterative ones it can be observed that, in general, they are similar in case of three methods: pattern, anti-pattern and classical method (values in bold in Table 4). The relatively largest differences in the values of aggregate indexes occur in case of the anti-pattern method, and the results obtained using pattern method differ the most from the method referred to as the classical one. Table 4 lists the ranks of provinces based on the values of indexes from Table 2. The similarity of ordering was assessed using the Spearman's rank correlation coefficient (Table 5).

Table 4. Ranks of provinces based on the values of Relative Index of Industrial Enterprise Innovation Activity, calculated for Polish provinces, for 2015 [7].

\begin{tabular}{|c|c|c|c|c|c|c|}
\hline Province & \multicolumn{2}{|c|}{ Pattern method } & \multicolumn{2}{|c|}{ Anti-pattern method } & \multicolumn{2}{|c|}{ Classical method } \\
\hline Dolnośląskie & 8 & 9 & 6 & 6 & 4 & 4 \\
\hline Kujawsko-pomorskie & 11 & 11 & 11 & 11 & 13 & 13 \\
\hline Lubelskie & 13 & 15 & 12 & 12 & 10 & 11 \\
\hline Lubuskie & 14 & 13 & 13 & 13 & 14 & 15 \\
\hline Łódzkie & 15 & 14 & 15 & 15 & 15 & 14 \\
\hline Małopolskie & 4 & 4 & 5 & 5 & 6 & 6 \\
\hline Mazowieckie & 6 & 6 & 7 & 7 & 7 & 7 \\
\hline Opolskie & 7 & 7 & 4 & 4 & 5 & 5 \\
\hline Podkarpackie & 3 & 3 & 2 & 2 & 2 & 3 \\
\hline Podlaskie & 1 & 1 & 1 & 1 & 1 & 1 \\
\hline Pomorskie & 9 & 8 & 8 & 8 & 11 & 10 \\
\hline Śląskie & 2 & 2 & 3 & 3 & 3 & 2 \\
\hline Świętokrzyskie & 16 & 16 & 16 & 16 & 16 & 16 \\
\hline Warmińsko-mazurskie & 12 & 12 & 14 & 14 & 12 & 12 \\
\hline Wielkopolskie & 5 & 5 & 10 & 10 & 9 & 9 \\
\hline Zachodniopomorskie & 10 & 10 & 9 & 9 & 8 & 8 \\
\hline
\end{tabular}


Table 5. Rank correlation coefficients for provinces by innovation indexes.

\begin{tabular}{lccccccc}
\hline \multicolumn{2}{c}{ Specification } & \multicolumn{2}{c}{ Pattern method } & \multicolumn{2}{c}{ Anti-pattern method } & \multicolumn{2}{c}{ Classical method } \\
& & original & iterative & original & iterative & original & iterative \\
\hline Pattern & classical & 1 & $\mathbf{0 . 9 8 8}$ & 0.926 & 0.926 & 0.906 & 0.918 \\
method & iterative & $\mathbf{0 . 9 8 8}$ & 1 & 0.909 & 0.909 & 0.859 & 0.879 \\
Anti- & classical & 0.926 & 0.909 & 1 & $\mathbf{1 . 0 0 0}$ & 0.956 & 0.956 \\
pattern & iterative & 0.926 & 0.909 & $\mathbf{1 . 0 0 0}$ & 1 & 0.956 & 0.956 \\
method & & & & & & & \\
Classical & classical & 0.906 & 0.859 & 0.956 & 0.956 & 1 & $\mathbf{0 . 9 9 1}$ \\
method & iterative & 0.918 & 0.879 & 0.959 & 0.959 & $\mathbf{0 . 9 9 1}$ & 1 \\
\hline
\end{tabular}

Index values, according to the pattern and anti-pattern method can be combined into one indicator by an arithmetic or geometric mean. In the presented study it was decided to use the geometric mean. The results are presented in Table 6.

Table 6. The values of Relative Index of Industrial Enterprise Innovation Activity, calculated for Polish provinces, for 2015, obtained using combined pattern-anti-pattern method, and ranks of provinces.

\begin{tabular}{lcccc}
\hline \multirow{2}{*}{ Province } & \multicolumn{2}{c}{ Index values } & \multicolumn{2}{c}{ Ranks } \\
& original & iterative & original & iterative \\
\hline Dolnośląskie & 40 & 39 & 6 & 6 \\
Kujawsko-pomorskie & 30 & 25 & 11 & 11 \\
Lubelskie & 26 & 21 & $\mathbf{1 3}$ & $\mathbf{1 4}$ \\
Lubuskie & 24 & 22 & $\mathbf{1 4}$ & $\mathbf{1 3}$ \\
Lódzkie & 21 & 19 & 15 & 15 \\
Małopolskie & 46 & 45 & 4 & 4 \\
Mazowieckie & 39 & 35 & 7 & 7 \\
Opolskie & 42 & 42 & 5 & 5 \\
Podkarpackie & 53 & 54 & 3 & 3 \\
Podlaskie & 81 & 81 & 1 & 1 \\
Pomorskie & 37 & 34 & $\mathbf{9}$ & $\mathbf{8}$ \\
Śląskie & 56 & 57 & 2 & 2 \\
Świętokrzyskie & 10 & 14 & 16 & 16 \\
Warmińsko-mazurskie & 26 & 23 & 12 & 12 \\
Wielkopolskie & 38 & 33 & $\mathbf{8}$ & $\mathbf{9}$ \\
Zachodniopomorskie & 35 & 31 & 10 & 10 \\
\hline
\end{tabular}

To sum up, it should be stated that, as in other applications of an iterative procedure, the ranking changes are quite small, but for local authorities even those small changes could be considered important, especially when the country consist of not so many administrative units of NUTS 2 level.

\section{Conclusions}

The example covering a relatively small number of objects was selected to illustrate the problem in order to allow the Reader, track changes in their ordering for each method. 
In case of enterprises' innovation assessment against the classical version, the ranking changes were recorded for the following provinces:

- Dolnośląskie, Lubelskie, Lubuskie, Łódzkie and Pomorskie - in the iterative pattern method,

- Lubelskie, Lubuskie, Łódzkie as well as Pomorskie and Śląskie - in the iterative method.

All (applied) methods indicated that in 2015 the highest innovation activity was characteristic for industrial enterprises in Podlaskie province. It seems that the patternanti-pattern development method is a valuable one, both in the original and iterative version, as it combines the results of methods using two extreme reference points through the geometric mean.

Acknowledgements. The study carried out within the framework of the project no. 2015/17/B/HS4/01021, entitled Smart growth vs. sectoral transformations in the European regional space - measurement methods, financed by the National Science Centre in Poland.

\section{References}

1. Central Statistical Office, Statistical Office in Szczecin: Innovative activity of enterprises in the years 2013-2015. Warsaw (2016).

2. Chen S.J., Yoon K.: Fuzzy Multiple Attribute Decision Making. Methods and Applications. Springer Verlag, Berlin (1992)

3. Freudenberg, M.: Composite Indicators of Country Performance: A Critical Assessment. OECD Science, Technology and Industry Working Papers 2003/16. OECD Publishing, Paris, (2003).

4. Hellwig, Z.: Application of the taxonomic method in the typological division of countries in terms of development and the structure of qualified personnel, Statistical Review, No. 4, 323-326 (1968).

5. Hwang, C.L., Yoon, K.: Multiple Attribute Decision Making: Methods and Applications, Springer-Verlag, Berlin (1981).

6. Markowska, M., Sokołowski, A.: Iterative Method for Linear Ordering of Multidimensional Objects, Statistical Review, R. LXIV, Journal 2, 153-162 (2017).

7. Markowska, M., Strahl, D.: Relative Index of Enterprise Innovation Activity for Polish provinces, in: Proceedings of the 11th Professor Aleksander Zeliaś International Conference on Modelling and Forecasting of Socio-Economic Phenomena / Papież, M., Śmiech, S. (eds.), 2017, Foundation of the Cracow University of Economics, 231-240 (2017).

8. OECD, JRC European Commission: Handbook on Constructing Composite Indicators. Methodology and Users Guide. (2008)

9. Sager, A.D., Najam, A., The Human Development Index: A Critical Review. Ecological Economics, 25, 249-264 (1998) 
10. Saisana, M., Saltelli, A., Tarantola, S.: Uncertainty and sensitivity analysis techniques as tools for the quality assessment of composite indicators. Journal of the Royal Statistical Society, A, 168, Part 2, 307-323 (2005)

11. Saisana, M., Tarantola, S.: State-of-the-Art Report on Current Methodologies and Composite Indicator Development. European Commision, Joint Research Centre. Ispra (2002)

12. Sen A.: A Decade of Human Development, Journal of Human Development, (1), 17-23 (2000)

13. Stanton, E.A.: The Human Development Index: A History. Political Economy Reasearch Institute. Workingpaper Series, Number 127. Amherst (2007) 